\title{
Addressing Intimate Partner Violence using Gender Responsive Approaches at a Community Level in Rural Tanzania: The UZIKWASA programme
}

\begin{abstract}
Intimate partner violence (IPV) is recognised as an important public health and social problem, with far reaching consequences for women's physical and emotional health and social well-being, yet little is known about how behaviour change campaigns impact on this type of behaviour and other related abuses in Tanzania and in other sub-Saharan African countries. UZIKWASA is a civil society organization based in Pangani District in coastal Tanzania and since 2009 has conducted Behaviour Change Campaigns (BCCs) focused on promoting gender justice and effective leadership. As with other complex programmes there is a question about how such approaches affect norms and practice in relation to violence against women and girls. Drawing on longitudinal research utilising over 1000 community diary entries (hearsay ethnographies) and qualitative methods using 20 in-depth interviews and 16 focus group discussions with women and men, and adolescent girls and boys, this paper explores the ways in which UZIKWASA's programme effects change. The findings reveal personal and community narratives about gender-based and intimate partner violence as forms of retributive justice and assertion of authority by men. Drawing on gender performance as an explanation for violence, the research revealed changes in norms and practice in relation to violence against women and girls. Thus, we argue that UZIKWASA is gender-transformative by addressing gender norms, and the critical awareness amongst leaders and the community of the social construction and reconstruction of gender that creates the context for real impact on changes in behaviour.
\end{abstract}




\section{Background}

Intimate partner violence (IPV), involving physical, sexual, economic, emotional abuse as well as controlling behaviour, is recognised as an important public health problem, development issue and human rights concern. Globally, it is estimated that about $30 \%$ of women will experience physical and/or sexual violence from an intimate partner during their lifetime (Devries et al., 2013), and that one in three homicides among women are by an intimate partner (Stöckl et al., 2013). In Tanzania, 42\% of women aged 15-49 have ever experienced physical and/or sexual violence and 30\% in the past 12 months (National Bureau of Statistics, United Republic of Tanzania, 2016). However, there are higher levels in parts of Tanzania. For example, in Mwanza, a baseline survey for a randomised cluster controlled study revealed that $61 \%$ of women reported ever experiencing physical and/or sexual IPV and 27\% experienced it in the past 12 months (Kapiga et al., 2017).

Experience of IPV has far reaching consequences for women's physical and emotional health and social well-being (Ellsberg, Jansen, Heise, Watts, \& Garcia-Moreno, 2008; World Health Organization, 2013). Women who experience IPV show more physical symptoms of poor health, and more days out of work and injuries than women who have not been abused (Dillon, Hussain, Loxton, \& Rahman, 2013; Ellsberg et al., 2008). IPV has also been associated with mental health problems, including depression, anxiety, phobias, post-traumatic stress disorder, suicide, and alcohol and drug abuse (Dillon et al., 2013; Mahenge, Likindikoki, Stöckl, \& Mbwambo, 2013; World Health Organization, 2013). Furthermore, evidence suggests that controlling behaviour, where the male partner uses threats to maintain control over the woman, has a similar impact on women's well-being (Antai, 2011; Krantz \& Vung, 2009). 


\section{Approaches to Preventing Intimate Partner Violence}

Several intervention studies have been implemented in low and middle income countries to address IPV (Abramsky et al., 2014; Garcia-Moreno, 2002; Pronyk et al., 2006; Ramsay et al., 2009). Programmes that have been found to be effective are often participatory and promote discussion about gender, power and violence, to support greater communication and shared decision making among family members, as well as non-violent behaviour (Ellsberg et al., 2015a). For example, the Intervention with Microfinance for AIDS and Gender Equity (IMAGE) trial implemented in rural South Africa, found that participatory sessions for women promoting gender empowerment linked to microfinance loans was associated with $55 \%$ reduced IPV incidence in the past year (Pronyk et al., 2006).

Michau (2015) argues, however, that the prevention of violence against women and girls cannot be achieved by one institution, sector, or group working in isolation and instead cross-sectoral coordination is essential and mutual reinforcement of programming helps to increase overall effectiveness while optimising resources (Michau, Horn, Bank, Dutt, \& Zimmerman, 2015). These approaches include multi-sectoral programmes that engage with multiple stakeholders to transform deeply entrenched attitudes and behaviours by challenging the acceptability of violence and gender norms or focus on community mobilisation to achieve community level effects (Ellsberg et al., 2015b). These include campaigns such as the "Bell Bajao" campaign which utilises multimedia with grassroots community mobilisation to shift norms and behaviours around IPV and women living with HIV (OneWorld Foundation India, 2011). Such campaigns draw on local discourses to challenge community and individual dynamics related to violence and work with men as well as women.

\section{Gender Inequalities in Tanzania}


Whilst there have been some improvements in access for women to political power over the last few decades, inequalities between women and men still exist in the arena of economic power, including, access to education, work, land and property (Meena, 2009). These disparities start early with higher levels of secondary level education achieved by boys (12\%) compared with girls (8\%) (fhi360, 2012).In terms of land ownership, approximately $98 \%$ of economically active rural women are engaged in agriculture but only $20 \%$ own titled land and the land they own is smaller on average than that owned by men (Lacey Harris-Coble, 2016). Despite plans to reform customary laws of inheritance, they still prevail for a large percentage of the patrilineal groups. Thus women continue to have a lack of control of property during marriage, and at divorce or widowhood, and, despite the 1999 Land Act, have limited access to credit (Liljeström et al., 1998; OECD, 2011).

UZIKWASA is a civil society organization based in the Pangani district in the Tanga region of Tanzania, covering 33 villages with a population of around 60,000 people. Taking a multi-sectoral and community mobilisation approach, UZIKWASA has developed a set of integrated interventions that focus on addressing gender inequalities, as well as gender-based violence. This includes communication and dialogue campaigns utilising Theatre for Development (TfD), videos, films and magazines and a community radio (Pangani FM); gender transformative leadership training, and camps that involve a number of village activities over a three-day period to address gender equality and gender-based violence. Starting in 2016, UZIKWASA has focused its interventions to improve prevention and response to intimate partner violence (IPV). This includes the Minna Dada ('I have a sister') campaign that focuses an integrated intervention package on solidarity in addressing gender inequalities. Its main features are workshops (Minna Dada Camps) with multi-sectoral stakeholders in all of Pangani District's 33 villages and additional leadership training at the overall district level. (UZIKWASA, 2018). 
Drawing on both innovative and traditional qualitative research methods, this paper aims to explore the ways in which UZIKWASA's interventions affect attitudes and norms surrounding violence against women and girls.

\section{Methods}

Two qualitative methods were utilised to explore changes in norms and practices in relation to violence against women and girls. The first approach - hearsay ethnographies - captured data over a five-year period from 2010 - 2015. The second approach - cross-sectional IDIs and FGDs - captured data in 2017 immediately after the implementation of UZIKWASA's Minna Dada campaign.

\section{Hearsay Ethnographies}

Hearsay ethnographies were developed by Watkins and Swidler (2007) to capture how meaning is produced and re-produced in everyday life. The authors recruited high school graduates to be participant observers as part of their daily routines by recording conversations they overheard about AIDS, and write their recollections in school notebooks soon after. They found that the captured texts provided an opportunity for researchers to overhear everyday conversations in natural settings. This method was adapted by ND and UZIKWASA to capture changing norms and practice in relation to key areas of their programmes including: early forced marriage; education support \& gender equitable parenting, caregiver responses to sexual abuse \& early pregnancy, and sexual and gender-based violence.

In order to implement this method, ND and the UZIKWASA team trained 10 men and women from 5 villages to record conversations that reflected the above themes. They were provided with notebooks and on a bi-monthly basis visited by the UZIKWASA monitoring and evaluation officer who collected 
the diaries and provided new notebooks. Data was collected, transcribed and coded over a five-year period from November 2010 to October 2015. (See Figure 1 for timeline). The study collected over a thousand diary entries from men and women in five villages in Pangani District: Pangani West, Kipumbwi, Mwera, Mkalamo and Kigurusimba. The villages were purposively selected to provide a broadly representative sample of the district comprising a mix of urban/rural, easy access/hard to reach, coastal/inland, secondary and primary school/primary school only, high migration/low migration, diverse economy/mostly agricultural economy, proximity to plantation, north/south of Pangani River. In 2016, MM conducted an in-depth analysis of the data in relation to the key themes (UZIKWASA, 2017).

\section{In-depth Interviews and Focus Group Discussions}

To address individual and community experiences of UZIKWASA's programmes, and explore changes in norms and practices, a cross-sectional qualitative approach was taken utilizing focus group discussions (FGDs) and in-depth interviews (IDIs) in 2016 (see Figure 1 for timeline). In four of the five villages where the hearsay ethnographies had been situated and the Minna Dada programme had been delivered, IDIs were conducted with five participants who had attended the Mina Dada workshops and training (total: $20-6$ women, 14 men). In each village, four focus groups with 10 participants were conducted with men, women, girls and boys aged 15-18 years (total: 16 groups with 40 women, 40 girls 40 men and 40 boys). Convenience sampling was used to establish each of the groups by walking through the selected villages with a local leader inviting individuals to participate until 10 participants were recruited. The in-depth interviews and focus groups involved discussions on structural, socio cultural and individual factors associated with IPV, experiences of UZIKWASA' programmes, and perceived changes in norms and practices surrounding IPV. 
SL conducted training with six community development officers in interviewing skills and ethical conduct of research. All participants were asked to provide written informed consent. Adolescent participants were provided with a letter in Swahili with contact information to explain their participation to their parent/guardians. All participants were provided with a referral letter for support services for IPV or GBV. All IDIs and FGDs were conducted in Swahili in a private place of the participants choice. SL and MM co-facilitated the first four FGDs with the fieldworkers in village one. Following this, the fieldworkers conducted the remaining FGDs and IDIs.

\section{Analysis}

All diary entries were summarized with textual evidence to improve the manageability of the data set for deep analysis, and coded in MAXQDA using a mixed deductive method focusing on pre-determined themes (early forced marriage, sexual violence and gender-based violence, leadership and structural responses to violence, and parents attitudes to gender roles). This paper focuses on the findings that relate to sexual and gender-based violence.

For the IDI and FGD data all recordings were transcribed and translated then imported to MAXQDA project and coded within the existing coding framework with additional codes for intimate partner violence. Two themes were developed for this paper, which focused on community understanding of violence against women, and perceived changes and evidence of gender transformative change. Using an inductive approach, sub-themes were developed and reported below. 
Ethical approval for the study was provided by the London School of Hygiene and Tropical Medicine and the Tanzanian National Health Research Ethics Review Committee. In the quotes villages have been anonymised to preserve anonymity of participants.

\section{Context}

Pangani district is situated in the Tanga region on the East coast of Tanzania. In Tanga region $25 \%$ of women have ever experienced physical, sexual, or emotional violence (National Bureau of Statistics \& United Republic of Tanzania, 2015). Whilst this is lower than the prevalence recorded across Tanzania, a 2007 study conducted by UZIKWASA suggests that there are higher levels of violence. Using a mixed methods study design with cross sectional surveys and in-depth interviews combined with ethnographic and participatory data collection techniques, the study involved an in-depth exploration of the sociocultural context of gender and violence (UZIKWASA 2008). The findings revealed evidence of high levels of sexual violence towards women and girls, including gang rape. The drivers of gender-based violence identified included norms of early sexual initiation and forced early marriage, early socialisation of oppressive gender roles, acceptance of rape in marriage, high levels of alcohol consumption, community acceptance of violence against women and girls, victim blaming, nepotism and corruption, silence about violence due to shame and fear, and reluctance of leaders to take action to prevent and respond to violence. The findings from this study provided the basis for programme planning for UZIKWASA with a focus on challenging gender norms and effective leadership. 


\section{Findings}

\section{Community understanding of Violence against Women}

The findings presented here provide an insight into local understandings of violence against women, and how attitudes, and reported behaviours, related to violence have changed since the implementation of UZIKWASA's programmes.

\section{Hearsay: Gender-Based Violence as Retributive Justice}

Here we report on early narratives on violence captured in the conversational diaries between 2010 to 2012. Conversations about sexual violence at this time show nearly ubiquitous victim blaming and tend to narrate violence as a form of retributive justice towards women, and in some cases, men. The only conversations that did not condone gang rape focused on the consequences of contracting HIV. In Village A, when some boys bragged about gang raping a girl in secondary school one friend said to them, "You know, that is how AIDS is being spread easily because it is possible there was no one who used a condom."

In these early conversations, women and girls were permitted limited sexual expression, and rape, and especially gang rape, was commonly understood to be a way of controlling women's sexuality and their bodies. In one conversation, a group of men supported the gang rape of a girl: "Let her be taught a lesson ... Let her be sodomized until she dies.” A group of young men planned to gang rape a girl, saying, "She deserves to be gang raped because only two days ago she was caught having sex with [our friend] ... To whose place shall we take her?" Such punishment was also supported by women in this period. As one woman was heard to say "But that girl wanted that for herself. Otherwise, why did she go to the nightclub while she is still a student?". 
Conversations about intimate partner violence tended to cover the details of a public altercation or physical fight between partners. However, there were conversations around the use of retributive violence to support men's control of their wives. A man in Village D heard a woman screaming and on arrival, he found her being beaten by her husband, who was saying, "Let her be gang raped! She was crying for other peoples' husbands, so let her also be eaten!'” A bystander tells the diarist, "Let her be taught a lesson."

\section{Intimate Partner Violence as Assertion of Authority}

When asked about violence (utakili) or abuse (unyanyasaji) during FGDs and IDIs, women focused on men's use of violence to assert authority. Many women described experiencing physical violence (kupigwa) when they challenged men's authority or behaviour:

Village B FGD Women: He goes to a grocery, drinks alcohol with a woman and will end there, while I am in the house. I called him and asked him about that. He beat me severely and I had to be admitted at Bombo hospital.

Discussions often focused on how men justify the use of violence in intimate partner relationships when women's behaviour is perceived to be unreasonable, unacceptable or disrespectful to men.

Village D IDI School Committee Female Member: The husband may come home late; if he is asked "why?" This turns to be an offence by the wife; or when he returns from journey, but he did not leave food at home, and he is told "We have not cooked". This also turns to

\footnotetext{
${ }^{1}$ Eaten (Kuliwa) is a short hand for 'eat together' (Kula Mande), which is the term used for gang rape
} 
be an offence by the wife. So, she is beaten, badly. Or maybe when the husband returned the wife was at the neighbour's house, conversing.

Village A FGD Girls: You will see that in other places we, women have forgotten the marriage law which requires the man to be respected. You will see a man loves his wife, but she goes boasting, telling people, "I am controlling him. Whatever I tell him to do, he will do it, if I tell him to wash clothes for me, he will do so. Or if I tell him to do this or that, he does it”. So when the man hears this, he gets really annoyed, he decides it is better to beat her so that she understands him.

In line with the hearsay conversations men reiterated the notion of physical or sexual force as retributive justice.

Village C FGD Boys: ... you might find that the woman has side relationships (Mchepuko) and I might hear about it from other people. So if one day you annoy me I finish all my anger on you. In that situation neighbours will see it as the right thing to do because the woman has a bad habit.

Similarly, women's discussions on sexual violence focused on forced vaginal or anal sex as a form of control, with parallels with the use of gang rape to control women's behaviour. For some of the boys and men, sexual violence is also justified as a claim against the financial support provided by men: For example, sex. If the man wants to do sex and the woman refuses, while the man has undergone all the expenses that is when the man uses force (Village A FGD Boys). 
In the overlap of household resource negotiations, infidelity and partner violence, women often described infidelity as abuse, especially when men seek extra-marital relationships with younger women (nyumba ndogo - small house).

Village B FGD Women: ...once the husband has children with you he goes out and looks for young girls with pert breast. Therefore, you should prepare yourself, that "He can leave any time”.

This type of abuse was strongly linked to economic abuse, which women described as men's lack of financial support and neglect for the family: The man may have three concubines. He does not leave any money to the wife. (Village D FGD Girls). Economic abuse was also reported by both men and women as denying women their fair share of resources in divorce. A few women provided examples of economic abuse where men forced women to work as watumwa (slaves) on the farm, and took the income for that work or demanded access to profit they have made on their own business:

Village D Women FGD: The man asks her "What profit did you get?" The woman responds, "You ask me what profit I got. How much money did you give me? I looked for my own capital, you ask me so that I give you my capital, or you want to know what I have earned, does that concern you?" So, that is when you start fuss between the two of you. He says, "you live in my house and I ask you your profit, you don't want to give it to me". The wife says, "I can't give you because the capital was my own". The husband says, "Where would you get the money that makes you proud, had I not fed you?" So the arguments go on and on. But actually the woman is the one who carries $90 \%$ of the burden. You provide all the services in the house, he does not clothe you, and he does not treat you when you are sick, nothing, but he uses force on your right. 
Whilst some men acknowledged women's right to earn money independently, there was acknowledgement by both men and women that women can suffer violence if they earn money without their husbands' permission.

Village B FGD Women: Many men who get married don 't want their wives to do business, so that when they quarrel he can keep her withoutfood, so that she can adore him. And if you do business against his permission he will look for excuses, he will beat you and separate from you.

Controlling behavior was also discussed as a form of intimate partner violence. This overlapped with all forms of violence, as described above, controlling women through the assertion of authority. Included in these descriptions were the ways in which men controlled women's freedom (uhuru). As one woman said, control is: "Denying the woman freedom of speech. The man thinks he is the important person. When the woman shares her opinion he does not accept it. When you want to talk he tells you, 'you can't talk, because I am the father of the family and head of the family. ' Women also talked about limiting women's freedom in other ways, such as visiting friends or family.

Village A FGD girls: If you say, I want to go, if you say, I want to go home, he will ask "what for?" if you say "somebody is sick there" he will say "I shall go. You stay here" and if you have to go then both of you will go and come back together. When you reach there, you may not stay there overnight. You just see the sick person and come back, quickly.

\section{Gendered Explanations of Violence against Women}


Explanations of men's use of violence as retributive justice and authority focused on notions of masculinity and femininity that are seen to be cultural, traditional and religious: "The reason is cultural tradition. (He will say), 'As a man I am supposed to be above the woman. I cannot ignore our culture which has been followed by our ancestors. I cannot let a woman rule me" (Village D FGD Women). As many women noted, violence is a way for men to act or perform as a man.

Village D FGD Girls: It is a heritage, because the fathers and now the youth, for them beating is a 'fashion' like the way we change the wax 'vitenge' (wrap). If one does not beat his woman the other men would say to him, "Why didn't you beat your woman? You call him she is just quiet! If it were me I would beat her".

\section{UZIKWASA and Pangani FM: Evidence of Gender-Transformative Change}

Most of the FGD participants were aware of UZIKWASA and Pangani FM and had been exposed to a range of activities, including their media campaigns and training programmes.

Village D FGD girls: I participated. UZIKWASA's activities in our village - UZIKWASA helped to train people. They come with different issues! They stage performances and some people gain awareness, some don't. Also they disseminate announcements on time, giving us information which we did not know. Now we know. It has also given us a big awareness on strange occurrences which used to be kept secret. Now people speak out. Honestly, they have helped us a lot... We listen to the radio, "Aisha", Rukia chukua pipi” and violence.

Many of those exposed to UZIKWASA's programmes focused on the awareness they had gained about women's rights. 
Village A FGD Girls: There is a play, I am not sure whether it was performed by VMAC [leadership committee], but it is under UZIKWASA. You see a man with his wife have worked on the farm. The wife was divorced but she was not given what she deserved from the farm produce. However, from the day the performance was staged, when some of the people divorced their wives, they shared their property with their (former) wives. This means they had gained some knowledge.

Some men also revealed a new awareness of masculinity as a system of power and violence (mfumo dume - patriarchal system): "There is the patriarchal system, that also is violence. Men treat women like they are not human beings. Women are also human beings; they have the right to rest, she deserves compassion, we don't have compassion for our wives, we use the patriarchal system to justify: "Since I am the man she must do whatever I say.'”'(Village C FGD men). 'Mfumo Dume' undermines women's contribution to decision-making: "Even if I try to advise him he doesn't value my opinion, that is why we talked about male chauvinism” (Village C Matron IDI).

Women also challenged the notion of men's authority in the household, and instead argued that women carry the responsibility and burden of maintaining the household.

Village D FGD Women: If you see a child going to school, it is the mother's responsibility, not the father. If the child needs a school uniform, soap or two hundred shillings pocket money, the father is not concerned. All these responsibilities are the mother's burden, and we (mothers) also toil to earn the bread. We farm and come back home to start cooking.

Whilst reports of male power were used to explain violence there were narratives on gender equality: "Everybody in the relationship has equal rights. So, any shortage of rights to the other partner, and if 
the right is a legal one, that is violence" (Village B FGD men). Denial of rights (Haki) was frequently iterated by men and women as a form of violence: "to deny the woman her rights when you separate, while you accumulated wealth together, that is also violence" (Village C FGD men)

Whilst the narratives justifying GBV and IPV were an assertion of male authority there were many narratives from the IDI and FGD participants that challenge this justification of violence by men, especially the use of sexual violence as a way of controlling women

Village B FGD Men: You may want to have sex with your partner, but she does not want to do it. If you use force, then you have applied violence because you did it without her consent. If she takes you to court, you will be charged for having raped her. There were some narratives that reflected a better understanding about violence: "Yes it has changed because I understand that we used to look at violence from one side. But actually it is not just beating but denying somebody her basic rights is also violence. Therefore I have seen that. And also divorcing your wife, depriving her of freedom is also violence" (Village D IDI School Committee). Instances of awareness of perpetration of economic abuse were also present in men's accounts, which draw on UZIKWASA's focus on economic and land rights for women.

Village C FGD Men: For example, my partner and I are married, and we have poor life and God gave us inheritance and wealth, but one day I decided that everything that we own and accumulated together I will sell without her consent. Which in our surrounding community these cases are very common even though this education is provided through the television the radio. 
Whilst the focus of the discussions was on awareness, there were some interesting narratives about transformation. As one boy said: "The training takes somebody from one place to another place; that is this movement and education should not stop here" (Village D FGD Boys). Transformation was explained through the relational and performative process of film, theatre and radio, with the audience response in live events, or on Pangani FM, central to the transformation

Village A FGD Girls: To some extent the community is changing after watching the plays being staged - when it is said and enacted. So if the person mentioned has that habit he starts reforming slowly. After getting the message from Pangani FM, they reform. After the performance, if you did not go to the performance, when those who attended return home, you will hear them, "mama so and so! Tonight there was your true picture. They performed just as you do these things". So you learn "they have been acting my behavior, I must stop it." We are very thankful for changing this behavior. Some people change through Pangani FM when they feel ashamed and worrying that they may be seen even in the magazines or on the TV, they reform.

Transformation was also described at a personal level, especially for men who had attended the transformative leadership training. Aligning with UZIKWASA's approach to transformation one man who had attended the Minna Dada camp said: "I did not know that I commit intimate partner violence, but after attending that workshop I realised that Lo ${ }^{2}$ even I am among them!" (IDI Village D Patron). He then goes on to extend this realisation that such violence was widespread and implicated all men, including the male interviewer 'Na sio mimi tu, na wewe' (And not just me only, and you).

\footnotetext{
2 'Lo' is an expression of surprise
} 


\section{Perceived Reduction of Violence against Women and Girls in Pangani}

There were a number of discussions about the impact of the UZIKWASA programmes on the lives of girls, especially on the reduction of early and forced child marriages and pregnancies and school attendance for girls: "UZIKWASA has also made a big contribution to the community in fighting against the child marriages, encouraging education activities, like sending children to school, avoiding child marriages" (Village B FGD Men). There was also some evidence of structural change in response to this raised awareness of the rights of girls to education and this also contrasts with early diary study narratives that accepted early marriage for girls.

Village D FGD Men: The District Commissioner came here and said a vocational school will be built and that even if a girl does not pass her exams, she is still a student and should not be married. And it is true nowadays when a girl completes standard seven, she does not get married. Nobody wants his daughter to be married; everybody wants his children to go to school. This awareness was brought by UZIKWASA and Pangani FM.

In the final diary discussions in between 2013 and 2015 there are conversations that reflect changes in attitudes to sexual violence, including more emphatic speaking out against violence and increased support for victims of violence. In one conversation from Village B, a 14-year-old girl was leaving a disco at night when men surround her and threatened to gang rape her.: "I screamed and people came to help me... [One man] took me home from Sakura to Kipumbwi." In Village C, young men talked about a friend's mother who had been raped. After one man suggested it was her fault for walking alone, one of them pushed back: "Suppose she were your mother! How would you feel? Don't talk like that, and this should be your first and last time to say that.". 
There were also a number of conversations that suggested evidence for individual change. A man in Village D said: "Nowadays I see that you have really settled down. There are no quarrels. It is quite tranquil. That was due to alcohol, my brother, but I have seen its adverse effects... I don't want to beat a woman. Not only that, but if I am jailed, with whom shall I leave my family? ... When I beat their mother, the children were all crying like there was a funeral, on that day I saw that I was making my wife miserable." His friend reinforced his realization and decision to stop drinking and support his wife: "You have made a wise and sensible decision. Do your best, my brother. Your mother herself is a child, and you have her same spirit." Another Village D man, while discussing marriage, told his friend, "I don't have that habit of abusing a woman. I don't beat a woman'.

These perceived changes in violence in Pangani were iterated by the FGD and IDI participants. Village D FGD Boys: Raping was rampant; but after the establishment of UZIKWASA and PANGANI FM, the audio spots and the (drama/cultural) groups, somehow raping has diminished. ... If I consider Kigurusimba village every fortnight you would hear somebody has been gang raped. Or even in Pangani town you would hear something wrong was done to somebody at Mnyongeni yesterday. Nowadays you don't hear things like that.

Village D FGD Men: There were rape cases, they used to call them "mande” (gang rape). Gang rape cases were leading. One woman was raped by ten men. These cases were rampant, but UZIKWASA have been very useful, they have brought very important contribution, educating the community until now those cases have decreased, to a very big extent. 
Village D FGD Girls: Mostly gang raping has been reduced here, such cases are not there. It was rampant. When the women were drunk and fell asleep they were raped, but nowadays such cases have been reduced. We thank God.

\section{Improved Support for Victims of Violence}

In the early period of the hearsay conversations there was a lack of reporting on IPV or GBV by women due to fears of alienation or stigma. Even when cases were reported, there was complaints that systems responses were poor or there was impunity for perpetrators of gang rape: "Only yesterday someone was gang raped and this matter was taken to the leader, but he didn't take any action." There is some evidence in later diaries of improvements in support for women who have suffered violence, especially physical and economic abuse. In an entry from Village D, women discuss a woman who is abused by her husband: "I would have taken him to court and he would be giving the children's personal needs". There are several conversations about women taking men to court to demand contributions for family support, again pointing to the relationship between household resources and violence. However, there remained conversations about the impunity of wealthy and powerful perpetrators of sexual violence. For example, some men in Village D discussed the son of a village executive officer who is known to have raped multiple children but did not face charges because his father is an influential person. Furthermore, shame remained a pertinent reason for not seeking support following violence: "Those who are being sodomized are usually ashamed. They don't go to the police station to report. They remain quiet and that is why these incidents haven't completely stopped in this area". 
During the final diary collection period (2013-2015) there were conversations about improvement in leadership, police and legal support services for victims of gender and intimate partner-based violence. In Village B, a woman was overheard telling her friends that three male friends tried to rape her, but she escaped: "I have taken them to the chairman." A Pangani father discussed the recent gang rape of a young girl, saying of one perpetrator, "That guy was caught and taken to the police." When a perpetrator of gang rape in Village $\mathrm{C}$ admits, "It is true. I gang raped that woman because her husband is used to gang raping other people's children," a woman confronted him "You are the one who makes this problem continue in this area. You should know that we have lodged our complaint at the police station." Conversations reiterated UZIKWASA's messaging about violent sexual assault and their campaign against gang rape, specifically via Pangani FM. One man responds, pointing directly to changing behaviours: "No, you know, now even the rapists are educated... You think the [people] at Pangani FM talking about you every day would make you happy? People must change. They used to think it was praise."

Many participants in the FGDs and IDIs described changes in justice for victims of violence in line with the conversational diaries, especially improved support for victims by local leaders: I can say, in this place a few years ago there was no problem, but now the new community development officer follows up on partner violence cases on women. Even now when women face problems they just report them to the department (Village A FGD Girls). The improved response by social and legal services was noted amongst the leaders who had attended the UZIKWASA leadership training.

Village C IDI Religious Leader: UZIKWASA bring us together, so if you were doing something wrong now you know that you were wrong, because they involve the police officer, agricultural officer, fisheries officer or if you are the magistrate listening to that 
lesson of transformative leadership it touches you, you cannot escape it. If you're the magistrate and you were taking a bribe, now you will understand [the consequences]

This leadership training was seen as transformative at a community and structural level due to improved support for victims of violence as well as personally transformative.

Village A IDI VLC Member: There are violence cases like those which are brought to the village chairman. They say "chairman, my husband commits violence to me, he does one, two, three to me". I take it with both hands because UZIKWASA has already given us training and we are aware of ourselves. Nowadays, when we receive those cases we take them to the Community Development Officer. We take that kind of cass to him/her and they take it.

Village D FGD Men: UZIKWASA has reactivated the Village Committees. This has helped a lot because there was a time when the leaders did not know what they were doing. However, since the committees became active they follow up on the (village) government, to work with them and see if they are running the government properly for the people. .... This means had it not been UZIKWASA some of the leaders would be doing things their own way. So I am very grateful to these guys.

\section{Discussion}

The findings presented in this paper are drawn from data from both longitudinal and cross-sectional qualitative methods. The longitudinal method presented changing norms and practices related to public knowledge about sexual violence, especially gang rape. As Watkins and Swidler (2009) argue, the 
collection of hearsay conversations by different diarists over a long period of time provides insight into the ways in which 'local actors, pursuing their own agendas in a diversity of settings, actively reproduce the structures and meanings of their social world' without the dependence on cultural outsiders (p.3). The data captured here has revealed a brutal honesty about involvement in gang rape in the early diaries. Here the conversations were unfettered by social desirability bias, which can occur in interviews and discussions with cultural outsiders. The hearsay ethnographies revealed many perspectives over time, offered in situ, that may not otherwise be accessible through cross-sectional research conducted with cultural outsiders. The method does not, however, allow data collection focused on increases or decreases in a single empirical variable. Rather, it provides for the collection of conversations that reflect norms and practices that may be more useful for understanding how to effect change, and whose explanatory power may be stronger than traditional methods. Importantly, for UZIKWASA, this method also provides rich insight into the communities in which they work not just for $M \& E$ and impact assessment, but for deeper understanding to allow continuous responsive planning of programming.

The IDIs and FGDs, on the other hand, have captured highly nuanced discussions around IPV and explanations for its perpetration by men. They reveal norms and practices in relation to the perpetration of violence that are about men asserting power, through ideas authority and justice. They have revealed changing attitudes to hegemonic masculinity. Like the hearsay conversations, they also captured perceptions that violence against women and girls is decreasing in the community. As qualitative methods, they did not quantify or verify changes in levels of violence. Thus, the methods together affirm changing norms, and reports of behaviour change. 


\section{Gender Performance}

In gender-based violence research gender roles are often invoked to explain tensions between men and women, with a focus on the division of labour. However, it may be more useful to see gender not as a fixed attribute in a person but instead a fluid variable that can shift and change in different contexts and times (Butler, 1990). Being a gender is then an effect of acts based on cultural norms of being a "woman" and being a "man", which are contingent and open to negotiation in the determination of sexual meanings and sexual rights (Butler, 1990; Donnan \& Magowan, 2010). Merry (2009) has argued that gender based violence 'is always defined and redefined in interactions as it is performed for different audiences' (p.12). This research has revealed that violence against women in Pangani is a performance of masculinity, either in the public act of gang rape, or the private acts of intimate partner violence. Here, men have constructed masculine identities which are tied up with status and tradition in Pangani society. As Jakobsen (2014) argues, gender norms support violence, but violence also enforces the performance of gender, and maintains gender hierarchies (Jakobsen, 2014).

\section{Changing Norms and Practices in Relation to Gender}

The hearsay ethnographies reveal change, with more conversations that challenge acceptance of gang rape in later diaries, that suggest that this practice is becoming less acceptable. They also reveal a positive shift from blaming victims to blaming perpetrators of sexual and gender-based violence. Conversations reveal perceptions that there are decreases in rape and gang rape, and demonstrate higher expectations and confidence in local leaders and the police to respond to cases of violence.

UZIKWASA have focused their programmes on challenging gender norms. Whilst we see that the performance of masculinity is an explanation for violence, there is evidence that such ideas of 
masculinity are being challenged in Pangani. The findings present narratives challenging male patriarchy (mfumo dume) and personal testimonies of change, that are directly attributed to exposure to UZIKWASA's programmes. Whilst the performance of 'emphasized femininity' alongside masculinity provides an explanation for women's complicity in their own subordination (Connell \& Messerschmidt, 2005), this research has shown that women are challenging the notions of male dominance and asserting some nascent and some developed conceptions of gender equality.

Markovic (2003) argues that it is not possible to separate out gender from the political and social context in which it is produced and maintained (Markovic, 2003). UZIKWASA have contested norms and practices related to masculinity and femininity, by contextualising these at the local level. Leadership training to address gender rights has directly influenced those with political power and seen structural changes, including a more effective response to violence. In its media activities UZIKWASA highlights the contradictions that surround the performance of masculinity and femininity, especially the idea that gender roles are cultural, traditional, and religious. Drawing on local stories that include culture, tradition and religion, performances challenge static gender roles and instead present gender as fluid and adaptable to change, in line with gender performance theory. Thus, masculinity is not directly challenged but instead the contradiction in the performance of masculinity as violence is laid bare. We understand that gender transformative approaches are those that 'encourage critical awareness among men and women of gender roles and norms, promote the position of women, challenge the distribution of resources and allocation of duties between men and women; and/or address the power relationships between women and others in the community, such as service providers or traditional leaders' (Elisabeth, Schuler, \& Hardee, 2009, p.8). Thus we argue that UZIKWASA is gender-transformative by addressing gender norms, and the critical awareness amongst leaders and the community of the social 
construction and reconstruction of gender that creates the context for real impact on changes in behaviour.

\section{Conclusion}

The findings support UZIKWASA's approach that behaviour is socially contingent and changes in norms and practices around gender must be challenged at the community level with multi-sectoral involvement in gender justice. UZIKWASA's complex approach, including behavioural change campaigns that address community attitudes and interventions that support systems capacity to promote gender justice through reflective leadership, is promising for the prospect of continuing meaningful and durable change in Pangani. This, with its integrated programmes of response and evaluation allow for reflection, and enable UZIKWASA to ensure that their work is relevant to the communities in which it works and that its activities are consistently effective. 


\section{References}

Abramsky, T., Devries, K., Kiss, L., Nakuti, J., Kyegombe, N., Starmann, E., ... Musuya, T. (2014). Findings from the SASA! Study: a cluster randomized controlled trial to assess the impact of a community mobilization intervention to prevent violence against women and reduce HIV risk in Kampala, Uganda. BMC Medicine, 12(1), 1.

Antai, D. (2011). Controlling behavior, power relations within intimate relationships and intimate partner physical and sexual violence against women in Nigeria. BMC Public Health, 11, 511. https://doi.org/10.1186/1471-2458-11-511

Butler, J. (1990). Gender Trouble. New York: Routledge.

Connell, R. W., \& Messerschmidt, J. W. (2005). Hegemonic masculinity: Rethinking the concept. Gender \& Society2, 19(6), 829-859.

Devries, K. M., Mak, J. Y. T., García-Moreno, C., Petzold, M., Child, J. C., Falder, G., ... Rosenfeld, L. (2013). The global prevalence of intimate partner violence against women. Science, 340(6140), $1527-1528$.

Dillon, G., Hussain, R., Loxton, D., \& Rahman, S. (2013). Mental and physical health and intimate partner violence against women: a review of the literature. International Journal of Family Medicine, 2013.

Donnan, H., \& Magowan, F. (2010). The Anthropology of Sex. Oxford: Berg Publishers. Retrieved from $\mathrm{http}$ //books.google.com/books?id=Cdpcr5JVqOQC

Elisabeth, R., Schuler, S., \& Hardee, K. (2009). Gender Perspectives Improve Reproductive Health Outcomes: New evidence. U.S. Agency for International Development and Interagency Gender Working Group, 1977(8), 3231-3634. https://doi.org/10.1002/anie.197906331

Ellsberg, M., Arango, D. J., Morton, M., Gennari, F., Kiplesund, S., Contreras, M., \& Watts, C. (2015a). Prevention of violence against women and girls: What does the evidence say? The Lancet, 385(9977), 1555-1566. https://doi.org/10.1016/S0140-6736(14)61703-7

Ellsberg, M., Arango, D. J., Morton, M., Gennari, F., Kiplesund, S., Contreras, M., \& Watts, C. (2015b). Prevention of violence against women and girls: What does the evidence say? The Lancet, 385(9977), 1555-1566. https://doi.org/10.1016/S0140-6736(14)61703-7

Ellsberg, M., Jansen, H. A. F. M., Heise, L., Watts, C. H., \& Garcia-Moreno, C. (2008). Intimate partner violence and women's physical and mental health in the WHO multi-country study on women's health and domestic violence: an observational study. The Lancet, 371(9619), 1165-1172.

Garcia-Moreno, C. (2002). Dilemmas and opportunities for an appropriate health-service response to violence against women. The Lancet, 359(9316), 1509-1514.

Jakobsen, H. (2014). What's Gendered about Gender-Based Violence?: An Empirically Grounded Theoretical Exploration from Tanzania. Gender and Society, 28(4), 537-561. https://doi.org/10.1177/0891243214532311

Kapiga, S., Harvey, S., Muhammad, A. K., Stöckl, H., Mshana, G., Hashim, R., ... Watts, C. (2017). Prevalence of intimate partner violence and abuse and associated factors among women enrolled into a cluster randomised trial in northwestern Tanzania. BMC Public Health, 17(1), 190.

Krantz, G., \& Vung, N. D. (2009). The role of controlling behaviour in intimate partner violence and its health effects: a population based study from rural Vietnam. BMC Public Health, 9(1), 1.

Mahenge, B., Likindikoki, S., Stöckl, H., \& Mbwambo, J. (2013). Intimate partner violence during pregnancy and associated mental health symptoms among pregnant women in Tanzania: a cross $\square$ sectional study. BJOG: An International Journal of Obstetrics \& Gynaecology, 120(8), 940-947.

Markovic, L. (2003). Beyond binady opposition: de-gendering and redefining gender. Facta 
Universitatis, 2(10), 403-414.

Merry, S. E. (2009). Gender violence: A cultural perspective. Gender violence: A cultural perspective. Retrieved from https://search.proquest.com/docview/621800400?accountid=14744\%5Cnhttp://fama.us.es/search*s pi/i?SEARCH $=\% 5 \mathrm{Cnhttp}: / /$ pibserver.us.es/gtb/usuario_acceso.php?centro= $\$$ USEG\&centro $=\% 24 \mathrm{U}$ SEG\&d $=1$

Michau, L., Horn, J., Bank, A., Dutt, M., \& Zimmerman, C. (2015). Prevention of violence against women and girls: Lessons from practice. The Lancet, 385(9978), 1672-1684. https://doi.org/10.1016/S0140-6736(14)61797-9

National Bureau of Statistics, United Republic of Tanzania. (2016). Tanzania Demographic and Health Survey and Malaria Indicator Survey (TDHS-MIS) 2015-16. Dar Es Salaam, Tanzania, and Rockville, Maryland USA, 172-173. https://doi.org/10.1017/CBO9781107415324.004

National Bureau of Statistics, \& United Republic of Tanzania. (2015). Tanzania Demographic and Health Survey and Malaria indicator Survey. Retrieved from https://dhsprogram.com/pubs/pdf/fr321/fr321.pdf

OneWorld Foundation India. (2011). BELL BAJAO: End Domestic Violece against Women: Documentation of Best Practice.

Pronyk, P. M., Hargreaves, J. R., Kim, J. C., Morison, L. A., Phetla, G., Watts, C., .. Porter, J. D. H. (2006). Effect of a structural intervention for the prevention of intimate-partner violence and HIV in rural South Africa: a cluster randomised trial. The Lancet, 368(9551), 1973-1983.

Ramsay, J., Carter, Y., Davidson, L., Dunne, D., Eldridge, S., Feder, G., ... Warburton, A. (2009). Advocacy interventions to reduce or eliminate violence and promote the physical and psychosocial well-being of women who experience intimate partner abuse. Cochrane Database Syst Rev, 3.

Stöckl, H., Devries, K., Rotstein, A., Abrahams, N., Campbell, J., Watts, C., \& Moreno, C. G. (2013). The global prevalence of intimate partner homicide: a systematic review. The Lancet, 382(9895), 859-865.

UZIKWASA. (2017). UZIKWASA Diary Study Final Report.

UZIKWASA. (2018). UZIKWASA Website. Retrieved from https://www.uzikwasa.or.tz/

World Health Organization. (2013). Global and regional estimates of violence against women: prevalence and health effects of intimate partner violence and non-partner sexual violence. World Health Organization. 